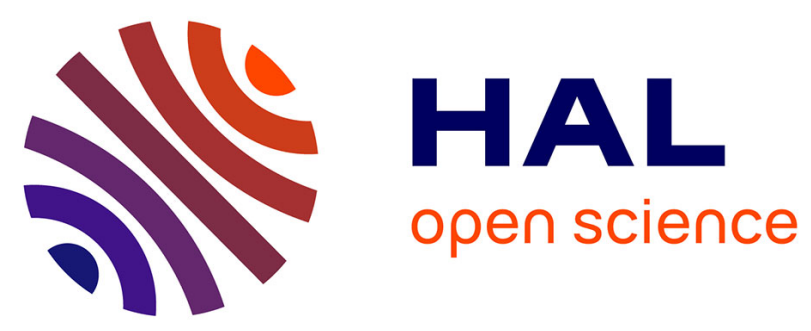

\title{
Analysis of a ten-year (1997-2007) record of time-varying gravity in Strasbourg using absolute and superconducting gravimeters: new results on the calibration and comparison with GPS height changes and hydrology
}

S. Rosat, J.-P. Boy, G. Ferhat, J. Hinderer, M. Amalvict, P. Gegout, B. Luck

\section{To cite this version:}

S. Rosat, J.-P. Boy, G. Ferhat, J. Hinderer, M. Amalvict, et al.. Analysis of a ten-year (1997-2007) record of time-varying gravity in Strasbourg using absolute and superconducting gravimeters: new results on the calibration and comparison with GPS height changes and hydrology. Journal of Geodynamics, 2009, 48 (3-5), pp.360. 10.1016/j.jog.2009.09.026 . hal-00594414

HAL Id: hal-00594414

https://hal.science/hal-00594414

Submitted on 20 May 2011

HAL is a multi-disciplinary open access archive for the deposit and dissemination of scientific research documents, whether they are published or not. The documents may come from teaching and research institutions in France or abroad, or from public or private research centers.
L'archive ouverte pluridisciplinaire HAL, est destinée au dépôt et à la diffusion de documents scientifiques de niveau recherche, publiés ou non, émanant des établissements d'enseignement et de recherche français ou étrangers, des laboratoires publics ou privés. 


\section{Accepted Manuscript}

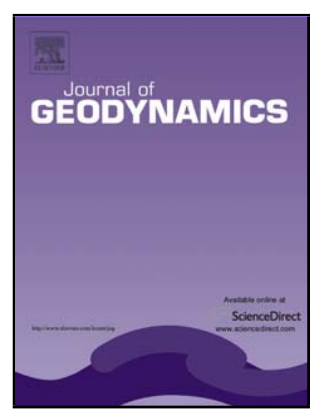

Authors: S. Rosat, J.-P. Boy, G. Ferhat, J. Hinderer, M.

Amalvict, P. Gegout, B. Luck

PII:

S0264-3707(09)00093-3

DOI:

doi:10.1016/j.jog.2009.09.026

Reference:

GEOD 920

To appear in: $\quad$ Journal of Geodynamics

Please cite this article as: Rosat, S., Boy, J.-P., Ferhat, G., Hinderer, J., Amalvict, M., Gegout, P., Luck, B., Analysis of a ten-year (1997-2007) record of time-varying gravity in Strasbourg using absolute and superconducting gravimeters: new results on the calibration and comparison with GPS height changes and hydrology, Journal of Geodynamics (2008), doi:10.1016/j.jog.2009.09.026

This is a PDF file of an unedited manuscript that has been accepted for publication. As a service to our customers we are providing this early version of the manuscript. The manuscript will undergo copyediting, typesetting, and review of the resulting proof before it is published in its final form. Please note that during the production process errors may be discovered which could affect the content, and all legal disclaimers that apply to the journal pertain. 
1 Analysis of a ten-year (1997-2007) record of time-varying gravity in Strasbourg using

4

absolute and superconducting gravimeters: new results on the calibration and comparison with GPS height changes and hydrology

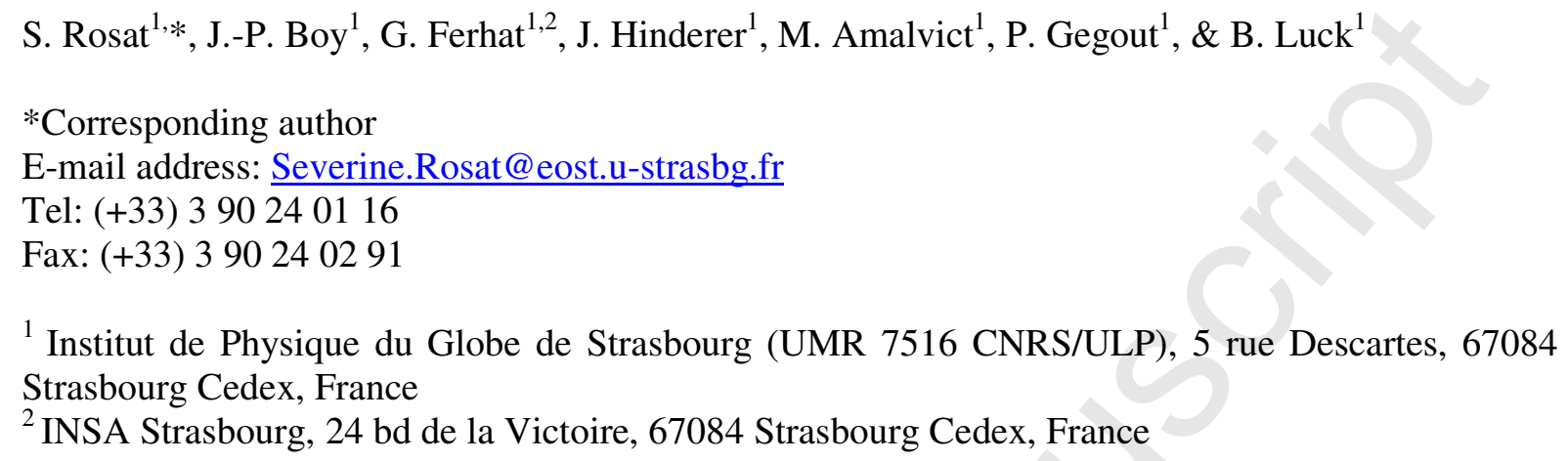
Strasbourg Cedex, France

\section{Abstract}

This paper is devoted to a detailed investigation of a continuous record spanning more than 10 years (1997-2007) of the Strasbourg superconducting gravimeter (SG GWR C026). We will first show the results from various scale factor experiments using parallel registrations with an absolute gravimeter (AG FG5\#206). These results will allow us to discuss the time stability of the calibration of the SG. Second, we will superimpose the AG and SG measurements to infer the long-term instrumental drift behavior of the SG but also the seasonal effects present at our station. These longterm effects will be discussed in terms of height changes by using collocated GPS measurements (since 1999) and in terms of hydrology (mainly with large scale hydrological models).

Keywords: SG calibration, inter-comparison of geodetic techniques, global hydrology model, GPS

\section{Introduction}

Since July 1996 the superconducting gravimeter (SG) GWR C026 is recording the timevarying gravity at the French J9 observatory in Strasbourg in the framework of the Global Geodynamics Project (GGP) (Crossley et al., 1999; Hinderer et al. 2004), although we are using here only gravity records since March 1997, after the upgrade of the acquisition system. In parallel to the SG measurements, absolute gravity (AG) measurements are performed routinely several 
1 times per year using the ballistic instrument FG5 \#206. It is well-established in the gravimetric

2 community that parallel AG measurements with the continuous SG records are primordial to

3 estimate and check the long-term stability of the SG instrumental drift. Besides, intensive AG

4 recording during several days are regularly performed to estimate the calibration factor of the SG

5 and to check its stability in time. The 10 -year SG records now available at the J9 site highlight the

6 presence of seasonal effects that we will interpret in terms of hydrology. Next, the long-term effects

7 and the seasonal variations are investigated in the vertical displacement given by GPS data. The

8 permanent GPS that belongs to the French geodetic network has been recorded since 1999 right on

9 the top of the building of the gravity station. The collocated GPS height changes help in separating

10 the gravity variation due to the vertical motion of the station from the variation due to the mass

11 redistribution.

\section{SG calibration}

The scale factor calibration of a relative SG can be done in several ways: 1/ by monitoring

15

16

17

the tides for a long period (2-3 years) and then use a well-known tidal amplitude (e.g. the diurnal wave $\mathrm{O}_{1}$ ) to calibrate the SG (Melchior, 1994); 2/ the use of a calibration platform (Falk et al., 2001); 3/ by moving an external mass (Achilli et al., 1995); 4/ by comparison with a reference instrument, especially an absolute gravimeter (Hinderer et al., 1991). Comparison with an absolute gravimeter is the most widely used method (e.g. Imanishi et al. 2002, Fukuda et al. 2005) to calibrate a relative gravimeter as it does not disturb the observational series of the SG and it also enables the investigation of the long-term drift of the SG (Francis et al., 1998). Since 1997, several calibration campaigns were performed at the J9 site. The time-length of the parallel registrations must be long enough (at least 5 days) to reach a reasonable accuracy on the scale factor estimate (Francis and van Dam, 2002). Therefore only the intensive campaigns, meaning at least 5 days of continuous AG measurements, are considered as useful for the scale-factor determination. The 
1 usual procedure to estimate the calibration factor is by least-squares fitting of the SG records to the

2 AG data points according to:

3

4

5

6

$$
y_{i}=a+b x_{i}
$$

where $y_{i}$ stands for the AG data and is expressed in $\mathrm{nm} / \mathrm{s}^{2}, x_{i}$ for the SG feedback output in volt (V), $b$ is the scale-factor expressed in $\mathrm{nm} / \mathrm{s}^{2} / \mathrm{V}$ and $a$ is the offset in $\mathrm{nm} / \mathrm{s}^{2}$. As the fit is better on high gravity signals, the tides are not removed from the signals. We use the set gravity values of the AG resulting from a statistical processing of the drop gravity values; a rejection criterion of outlier sets is applied at $1 \sigma$ (standard deviation), prior to the calibration. From the 1-min sampled SG records, we derive the SG value corresponding to the central time of the AG set before applying the linear least-squares method is applied. The raw SG records must have been corrected for any earthquake occurring at the time of calibration. AG set values are not perfect but contain some errors that we computed from the drop scatter. These standard deviations are used in the least-squares inversion in order to take into account the AG measurement errors; some clock problems can occur during the calibration experiments for instance that generate an error around $1 \mathrm{~nm} / \mathrm{s}^{2}$ (Van Camp et al. 2005).

The estimated scale factors for the various calibration campaigns are plotted in Fig. 1 for the period September 2002 - May 2008. As expected, the scale factor is stable in time, as there should be no changes in the magnetic fields of the upper and lower coils inducing the levitation of the niobium sphere inside the SG.

Note that because of the low instrumental drift of the SG (less than $15 \mathrm{~nm} / \mathrm{s}^{2}$ per year; see next part) and the short duration of each calibration campaign (the longest one was 12 days), this instrumental drift does not need to be removed for the linear regression fitting. The induced error lies within the error bars of the scale factors.

The weighted mean value leads to a scale factor of $-790.7+/-2.6 \mathrm{~nm} / \mathrm{s}^{2} / \mathrm{V}$, corresponding to a relative precision of $0.3 \%$. We have checked the decrease of the relative calibration error with the number of days of parallel AG measurements in Fig. 2 for the December 2004 campaign. Note that this calibration campaign was performed before the occurrence of the Sumatra earthquake. After 7 
1 days of parallel measurements, the uncertainty merely does not decrease any more and tends to 0.7

$2 \%$ for this specific campaign.

3 If we do not take into account the AG drop standard deviations, we obtain a value of -791.5

$4+/-0.5 \mathrm{~nm} / \mathrm{s}^{2} / \mathrm{V}$ for the calibration factor which corresponds to a relative uncertainty of $0.06 \%$. In

5 the past, Amalvict et al. (2001) performed estimates of the SG scale factor for the period March 1997 - April 2000. By combining their values with ours, we obtain the scale factors plotted in Fig.

71 (b) and the averaged value for the 10 years is $-791.8+/-0.25 \mathrm{~nm} / \mathrm{s}^{2} / \mathrm{V}$. This relative uncertainty is

8 smaller than the $0.1 \%$ accuracy required for a number of geophysical studies (nearly diurnal free

9 wobble, ocean and atmospheric loading, polar motion, anelasticity and tides...) as stated by Francis

10 et al. (1998) and Baker and Bos (2003).

\section{SG instrumental drift}

The SGs are known to be stable in time, as confirmed by the previous session, and to have a low drift. They are therefore useful instruments to record long-period geophysical signals (e.g.

Richter et al., 1995). By superposition with AG measurements, we can retrieve the purely instrumental part of the observed SG trend. This instrumental drift is defined as the total SG trend minus the observed trend in AG measurements. The AG trend is interpreted as a geophysical signal that could correspond to some long term deformations. Amalvict et al. (2004) have shown that the gravity was increasing in time at a rate of about $15.7 \mathrm{~nm} / \mathrm{s}^{2} / \mathrm{yr}$ from the beginning of 1997 to the end of 2002. In this paper, our data are spanning from the beginning of 1997 to the end of 2007, and the gravity increase observed in AG measurements is about $13.3 \mathrm{~nm} / \mathrm{s}^{2} / \mathrm{yr}$, while the SG instrumental drift is deduced to be $13.9 \mathrm{~nm} / \mathrm{s}^{2} / \mathrm{yr}$. In Fig. 3 we show the superposition of AG measurements with the SG record at Strasbourg from 1997 to 2007 before and after removal of the SG instrumental drift. Both AG and SG records have been corrected for the local tides, local atmospheric pressure using a barometric admittance of $-3 \mathrm{~nm} / \mathrm{s}^{2} / \mathrm{hPa}$ and for the polar motion effect. The pole tide, induced by polar motion and length-of-day variations, is modeled using daily Earth orientation 
1 parameters provided by the International Earth Rotation Service (EOPC04 series). The same

2 processes must be applied to both datasets for a rigorous comparison. The SG data were calibrated

3 using a scale factor of $-792 \mathrm{~nm} / \mathrm{s}^{2} / \mathrm{V}$, based on the previous AG calibration campaigns and were first

4 corrected for major instrumental perturbations such as gaps, spikes or offsets following the classical

5 procedure (Crossley et al. 1993) and were decimated to hourly samples using a low-pass filter with

6 a cut-off frequency of 12 cycles per day.

As we can observe on these plots, the gravity is smoothly increasing during the year 2001

and the observed drift seems to be different before and after 2001. This kind of feature could suggest that the SG instrumental drift would be better modeled by an exponential function of time as suggested previously by Van Camp and Francis (2006). However, when looking at the observed gravity increase in the AG data, we can notice that the gravity rate is also different before and after April 2001.

Before April 2001, the observed gravity increase from the AG measurements is 11.7 $\mathrm{nm} / \mathrm{s}^{2} / \mathrm{yr}$ leading to an SG linear instrumental drift of $13.1 \mathrm{~nm} / \mathrm{s}^{2} / \mathrm{yr}$. From the beginning of 2002 to the end of 2007, the observed gravity increase is only $1 \mathrm{~nm} / \mathrm{s}^{2} / \mathrm{yr}$ and the SG instrumental drift is 8.4 $\mathrm{nm} / \mathrm{s}^{2} / \mathrm{yr}$. From before and after 2001, the gravity increase rate has dropped by a factor 10 . The reason for this change of behavior has not been explained yet. Some local effects have to be investigated like, for instance, the local hydrology impact in 2001.

\section{Seasonal effects}

Besides the long-term drift of the time-varying gravity, the seasonal effects clearly appear in the SG residuals plotted in Fig. 4 (a) and (b). These seasonal effects can mostly be explained by the global hydrology loading as the contribution of the continental water storage changes (soil-moisture and snow) to gravity variations is one of the largest signal at seasonal timescales (Boy and Hinderer, 2006). Contrary to the part 3 when comparing SG with AG with the use of a constant barometric admittance, here we correct gravity variations for global atmospheric and induced non- 
1 tidal oceanic loading effects (Boy et al., 2002; Boy and Lyard, 2008) using global surface pressure

2 field provided by the European Centre for Medium-range Weather Forecasts (ECMWF), and sea-

3 surface height from the Toulouse Hydrodynamic Unstructured Grid Ocean model (HUGO-m)

4 barotropic ocean model (Carrere and Lyard, 2003) with a resolution of 0.5 degree and a temporal

5 sampling of 6 hours. In Fig. 5 we have superimposed the obtained SG residuals with the global

6 hydrology effects estimated from two different global models: ECMWF with temporal sampling of

76 hours and changing spatial sampling with the upgrades of the model (from 1.125 degree in 1997

8 to less than 0.25 after 2006), and GLDAS/Noah (Global Land Data Assimilation System) (Rodell et

9 al., 2004) with spatial sampling of 0.25 degree and temporal sampling of 3 hours. The outputs of

10 these models consist in soil moisture content, in equivalent snow height, and to a smaller extend

11 canopy water for GLDAS model. The hydrology effect is modeled as a thin-layer process acting on

a spherical Earth surface for which we model the direct Newtonian attraction and the elastic

loading. The local Newtonian contribution will have a sign different whether the station is buried in

14 the ground or if the station is located at the surface. In the case of the J9 SG site, the station is below the ground, so an excess of water mass will decrease the gravity. Note that the local

16 Newtonian attraction could be improved by taking into account the local topography of the site 17 (Longuevergne, 2008).

There is a correlation between our SG residuals and these estimated continental water storage loading effects. The correlation with the ECMWF model is of $42 \%$ for the period March 1997 - April 2001 and is of $64 \%$ for the period November 2001 - November 2007. The correlation with GLDAS model is $46 \%$ for the period March 2000 - April 2001 and $37 \%$ for the period November 2001 - December 2006. The ECMWF hydrological model better fits the SG residuals than GLDAS model. The difference between both hydrology models is as large as the difference between the computed hydrological effect and the gravity residuals. These discrepancies may be associated with local hydrology effects (see Longuevergne et al., 2008), which are not taken into 
1 three-dimensional model (Neumeyer et al., 2004) of air masses attraction in the neighborhood of the

2 gravimeter and a two-dimensional model of air masses attraction (Boy et al., 2002) far from the 3 station.

4

5

6

7

\section{GPS height changes}

We can explain most of the observed seasonal effects in gravity using a global hydrology model. Besides the purely Newtonian attraction, the global water masses contribute to elastically deform the Earth's surface. Such a vertical displacement should be visible by GPS. Above the SG instrument at Strasbourg J9 site, a GPS antenna has been recorded since 1999.

Generally, the hydrological loading caused by an excess in the soil water content leads to a decrease in height (subsidence) observable by GPS and to an increase in gravity observable by SGs. Hence the ratio of gravity change versus height change is always negative for this type of load (de Linage et al. 2007).

However since the Strasbourg SG station is below the ground, any excess of local water mass due to rain for instance will in fact decrease the gravity since the Newtonian local contribution dominates (see Boy \& Hinderer 2006; Longuevergne et al. 2008). This is why the signs of height and gravity are expected to be the same for our station (see Fig. 6).

We analyzed the GPS data from J9 site as well as other French (RENAG, webrenag.unice.fr) sites and European stations from the International Global Navigation Satellite System Service (IGS) network. We analyzed the GPS vertical displacement using the version 10.33 of GAMIT software. GPS Daily solutions are then combined using GLOBK software (Herring et al., 2006) to obtain times series of positions in an International reference frame, ITRF2005 (Altamimi et al., 2007).We have not applied any loading correction in order to compare the obtained displacements with our gravity residuals as obtained in section 3.

Before 2001, the GPS vertical displacement is very noisy, so we compare the GPS height changes with the SG residuals from 2002 only. They are superimposed in Fig. 6 where the daily 
1 GPS solutions were smoothed using an FFT filtering method. As expected, the seasonal effects are

2 also observed in the GPS height changes with a positive correlation between vertical displacement 3 and gravity.

4 If the seasonal effects observed in GPS height changes are due to the global hydrology 5 loading, there must be a correlation between the elastic loading effect in gravity and the vertical 6 displacement. We have plotted both signals in Fig. 7. The gravity contribution due to elastic 7 hydrology loading has been computed using GLDAS global model. This purely elastic gravity 8 effect has been converted into vertical displacement based on the ratio $-2 \mathrm{~nm} / \mathrm{s}^{2} / \mathrm{mm}$ which is a 9 mean value of the ratio over a large spectral range (see Fig. 5 of de Linage et al. 2007). The 10 seasonal variations observed in the GPS height changes are hence mostly explained by the elastic 11 loading of the continental water masses.

\section{Conclusion} determined to be $-791.8+/-0.25 \mathrm{~nm} / \mathrm{s}^{2} / \mathrm{V}(0.03 \%$ relative precision $)$ for the period March 1997 May 2008. From the beginning of 1997 to the end of 2007, the SG instrumental drift is equal to $13.9 \mathrm{~nm} / \mathrm{s}^{2} / \mathrm{yr}$. The observed AG gravity trend is different before and after April 2001, respectively of $11.7 \mathrm{~nm} / \mathrm{s}^{2} / \mathrm{yr}$ and $1 \mathrm{~nm} / \mathrm{s}^{2} / \mathrm{yr}$, suggesting that some unexplained local effects occurred during this period. In addition to long term trends, there are seasonal effects observed in the gravity residuals site which are mostly due to the local hydrological Newtonian effects, while the elastic effect of the continental water storage prevails in the observed seasonal GPS height changes at J9. The 2001 gravity increase cannot be explained by the global hydrological effects. Some other local effects must be investigated.

\section{Acknowledgments}


1 Continuous support of INSU-CNRS to operate the Strasbourg Gravity Observatory is 2 acknowledged. 


\section{Bibliography}

2 Achilli, V., Baldi, P., Casula, G., Errani, M., Focardi, S., Guerzoni, M., Palmonari, F. and Raguni,

3 G., 1995. A calibration system for superconducting gravimeters, Bull. Geod., 69, 73-80.

4 Altamimi, Z., X. Collilieux, J. Legrand, B. Garayt, and C. Boucher, 2007, ITRF2005: A new

5

6 release of the International Terrestrial Reference Frame based on time series of station positions and Earth Orientation Parameters, J. Geophys. Res., 112, B09401.

Amalvict, M., Hinderer, J., Boy, J.-P. and Gegout, P., 2001. A three year comparison between a superconducting gravimeter (GWR C026) and an absolute gravimeter (FG5\#206) in Strasbourg (France), J. Geod. Soc. Japan, 47, 334-340.

Amalvict, M., Hinderer, J., Mäkinen, J., Rosat, S. and Rogister, Y., 2004. Long-term and seasonal gravity changes at the Strasbourg station and their relation to crustal deformation and hydrology, J. of Geodyn., 38, 3-5, 343-353.

Baker, T. F., and M. S. Bos, 2003. Validating Earth and ocean tide models using tidal gravity measurements, Geophys. J. Int., 152, 468--485.

Boy, J.-P., and F. Lyard, 2008. High-frequency non-tidal ocean loading effects on surface gravity measurements, Geophys. J. Int., 175, 35-45.

Boy, J.-P., Gegout, P., Hinderer, J., 2002. Reduction of surface gravity data from global atmospheric pressure loading, Geophys. J. Int. 149, 534-545.

Boy, J.-P. and Hinderer, J., 2006. Study of the seasonal gravity signal in superconducting gravimeter data, J. of Geodyn., 41, 227-233.

Carrere, C. and F. Lyard, 2003. Modeling the barotropic response of the global ocean to atmospheric wind and pressure forcing - comparison with observations, Geophys. Res. Lett., 30 (6), 1275, doi:10.1029/2002GL016473.

Crossley, D.J., Hinderer, J., Jensen, O.G. and Xu, H., 1993. A slew rate detection criterion applied to SG data processing, Bull. Inf. Marees Terr., 117, 8675-8704.

Crossley, D., Hinderer, J., Casula, G., Francis, O., Hsu, H.T., Imanishi, Y., Jentzsch, G., 
Kääriäinen, J., Merriam, J., Meurers, B., Neumeyer, J., Richter, B., Shibuya, K., Sato, T., Van Dam, T., 1999. Network of superconducting gravimeters benefits a number of disciplines, EOS, $80,11,121 / 125-126$

de Linage, C., Hinderer, J. and Rogister, Y., 2007. A search for the ratio between gravity variation and vertical displacement due to a surface load, Geophys. J. Int., 171, 986-994.

Falk, R., Harnisch, M., Harnisch, G., Nowak, I., Richter, B. and Wolf, P., 2001. Calibration of the superconducting gravimeters SG103, C023, CD029 and CD030, J. Geod. Soc. Japan, 47, 22-27.

Francis, O., 1997. Calibration of the C021 superconducting gravimeter in membach (Belgium) using 47 days of absolute gravity measurements, International Association of Geodesy Symposia, 117, 212-219, Springer-Verlag.

Francis, O., Niebauer, T.M., Sasagawa, G., Klopping, F. and Gschwind, J., 1998. Calibration of a superconducting gravimeter by comparison with an absolute gravimeter FG5 in Boulder, Geophys. Res. Lett., 25, 7, 1075-1078.

Francis, O. and van Dam, T., 2002. Evaluation of the precision of using absolute gravimeters to calibrate superconducting gravimeters, Metrologica, 39, 485-488.

Fukuda, Y., Iwano, S., Ikeda, H., Hiraoka, Y. and Doi, K., 2005. Calibration of the superconducting gravimeter CT\#043 with an absolute gravimeter FG5\#210 at Syowa Station, Antarctica, Polar Geosc., 18, 41-48.

Herring, T. A., R. W. King, S. C. McClusky, 2006, Introduction to GAMIT/GLOBK, Release 10.3, Dept of Earth, Atmospheric, and Planetary Sciences, Massachusetts Institute of Technology.

Hinderer, J., Florsch, N., Mäkinen, J., Legros, H. and Faller, J.E., 1991. On the calibration of a superconducting gravimeter using absolute gravity measurements, Geophys. J. Int., 106, 491497.

Hinderer, J., \& Crossley, D., 2004. Scientific achievements from the first phase (1997-2003) of the Global Geodynamics Project using a worldwide network of superconducting gravimeters, J. Geodyn., 38, 237-262. 
1 Imanishi, Y., Higashi, T. and Fukuda, Y., 2002. Calibration of the superconducting gravimeter

2 T011 by parallel observation with the absolute gravimeter FG5 \#210-a Bayesian approach,

3 Geophys. J. Int., 151, 867-878.

4 Longuevergne, L., 2008. Contribution à l'hydrogéodésie, Univ. Pierre et Marie Curie, PhD Thesis.

5 Longuevergne, L., Gascoin, S., Rinaldi, S., Boy, J.-P., Ferhat, G., Ulrich, P., Florsch, N. and Hinderer, J., 2008. Local hydrological contribution in Strasbourg observatory, France, this issue.

Melchior, P., 1994. A new data bank for tidal gravity measurements (DB92), Phys. Earth Planet. $8 \quad$ Int., $82,125-155$.

9 Neumeyer, J., Hagedoorn, J., Leitloff, J., Schmidt, T., 2004. Gravity reduction with threedimensional atmospheric pressure data fro precise ground gravity measurements, J. of Geodyn. 38, 437-450.

Richter, B., Wenzel, H.-G., Zürn, W. and Klopping, F., 1995. From Chandler wobble to free oscillations: comparison of cryogenic gravimeters and other instruments in a wide period range, Phys. Earth Planet. Int. 91, 131-148.

Rodell, M., Houser, P.R., Jambor, U., Gottschalck, J., Mitchell, K., Meng, C.-J., Arsenault, K., Cosgrove, B., Radakovich, J., Bosilovich, M., Entin, J.K., Walker, J.P., Lohmann, D., Toll, D., 2004. The global land data assimilation system, Bull. Am. Met. Soc. 85, 381-394.

Tamura, Y., Sato, T., Fukuda, Y. And Higashi, T., 2001. Scale factor calibration of a superconducting gravimeter at Esashi Station, Japan, using absolute gravity measurements, J. of Geodesy 71: doi 10.1007/s00190-004-0415-0.

Van Camp, M., Williams, S.D.P., Francis, O., 2005. Uncertainty of absolute gravity measurements, J. Geophys. Res., 110, B05406, doi:10.1029/2004JB003497.

Van Camp, M. and Francis, O., 2006. Is the instrumental drift of superconducting gravimeters a linear or exponential function of time?, J. of Geodesy, DOI 10.1007/s00190-006-0110-4. 


\section{Figure caption}

2 Fig. 1 Time stability of the calibration factor of the GWR C026 at Strasbourg (J9). (a) From

3 September 2002 to May 2008. The column bars represent the number of sets used for the inter-

4 comparison with the AG measurements and the number indicates the number of days the parallel

5 registration with the AG was performed. The least-square fitting was made with the AG standard

6 deviations as weights. (b) From March 1997 to May 2008. The averaged scale factor value is -791.8

$7+/-0.25 \mathrm{~nm} / \mathrm{s}^{2} / \mathrm{V}$. Each observation is considered having the same weight (equal to one) in the least-

8 square adjustment.

9 Fig. 2 Relative precision on the scale factor of the C026 superconducting gravimeter at Strasbourg

10 in function of the number of observation days of absolute gravity measurements with the FG5 \#206

11 during the December 2004 calibration campaign.

12 Fig. 3 Superposition of AG FG5\#206 measurements and SG GWR-C026 time-varying gravity at

13 Strasbourg from March 1997 to December 2007. The upper plot represents the SG time-varying

14 gravity without correction of the SG instrumental drift and the lower plot represents the

15 superposition after removing the instrumental part from the SG trend. The estimated linear

16 instrumental drift between 1997 and 2007 has been estimated to $13.9 \mathrm{~nm} / \mathrm{s}^{2} / \mathrm{yr}$.

Fig. 4 Superposition of AG FG5\#206 measurements and SG GWR-C026 time-varying gravity at

Strasbourg (a) before April 2001 and (b) after 2001. The left-hand plots represent the SG time-

varying gravity without correction of the SG instrumental drift and the right-hand plots represent

the superposition after removing the instrumental part from the SG trend. The estimated linear

21 instrumental drift of the SG between 1997 and April 2001 is $13.1 \mathrm{~nm} / \mathrm{s}^{2} / \mathrm{yr}$, and between 2002 and

22 end of 2007 it is $8.4 \mathrm{~nm} / \mathrm{s}^{2} / \mathrm{yr}$. The observed gravity increase rate before April 2001 is $11.7 \mathrm{~nm} / \mathrm{s}^{2} / \mathrm{yr}$

23 and after 2001 it is $1 \mathrm{~nm} / \mathrm{s}^{2} / \mathrm{yr}$.

24 Fig. 5 SG gravity residuals and global hydrology effects at Strasbourg, J9 site before (left-hand) and

25 after (right-hand) 2001. In blue we have represented the continent water content effect using

26 GLDAS global model and in red using the ECMWF model of soil moisture and snow. 
1 Fig. 6 SG gravity residuals (in black) and GPS height changes (in blue) observed at Strasbourg, J9

2 site from 2002 to late 2007. Note the positive correlation between both signals due to the fact that

3 the local hydrological masses dominate and are located above the SG.

4 Fig. 7 GPS height changes (in blue) and elastic loading effect from the global GLDAS hydrology

5 model (in black). The hydrology elastic loading has been multiplied by $-0.5 \mathrm{~mm} / \mathrm{nm} / \mathrm{s}^{2}$ in order to

6 convert the elastic gravity effect into vertical displacement. 


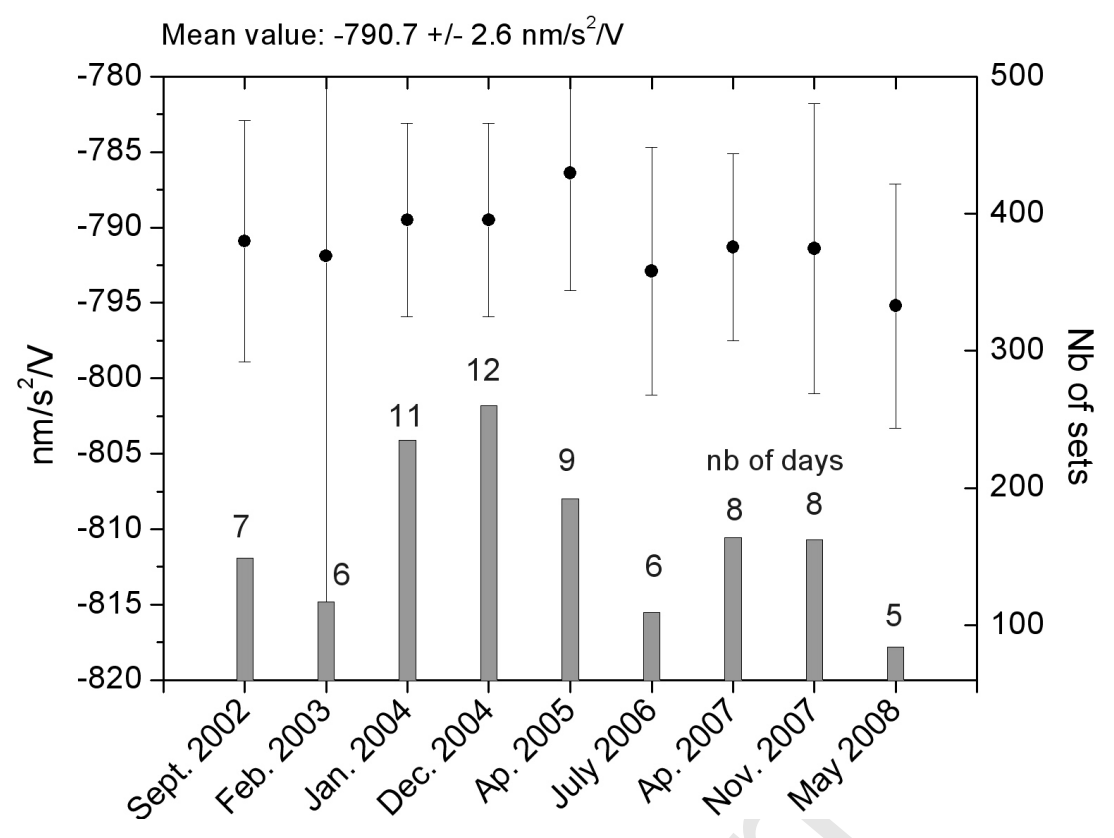

Fig.1 (a)

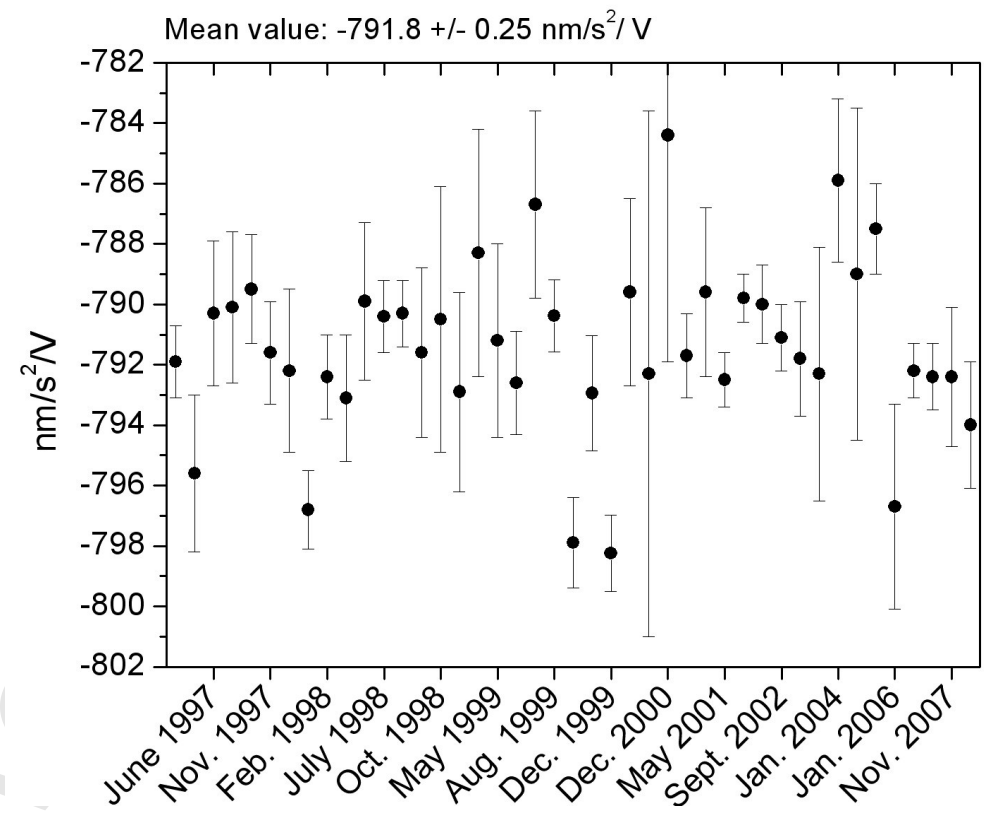

Fig. 1 (b) 


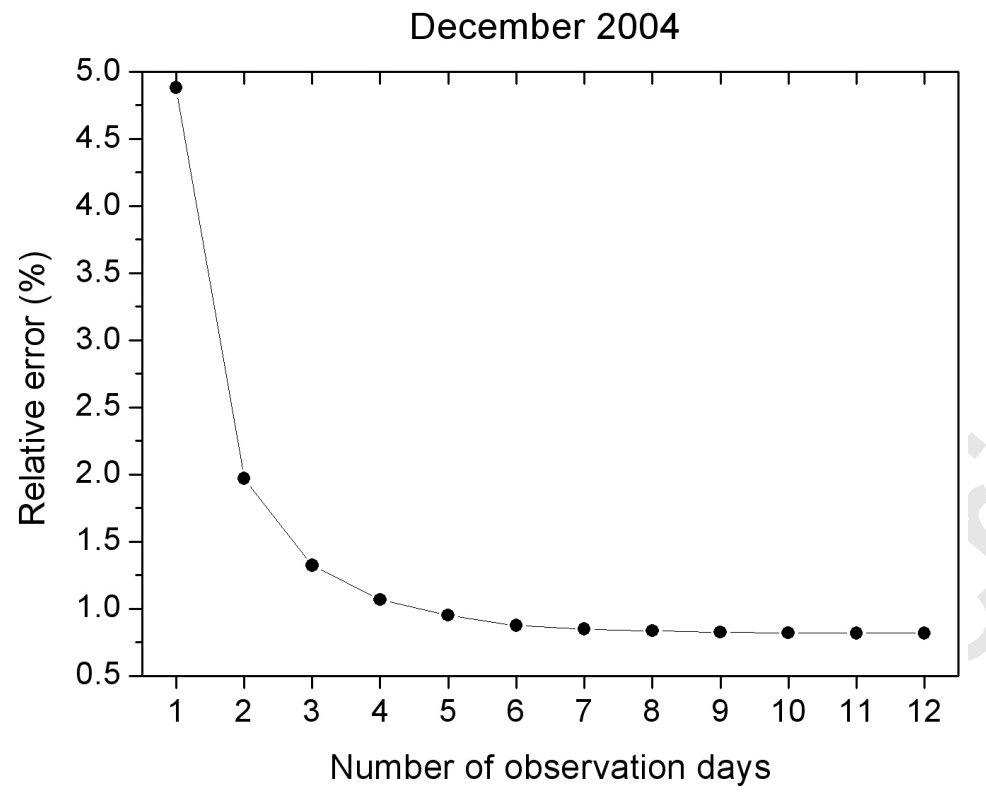

Fig. 2 


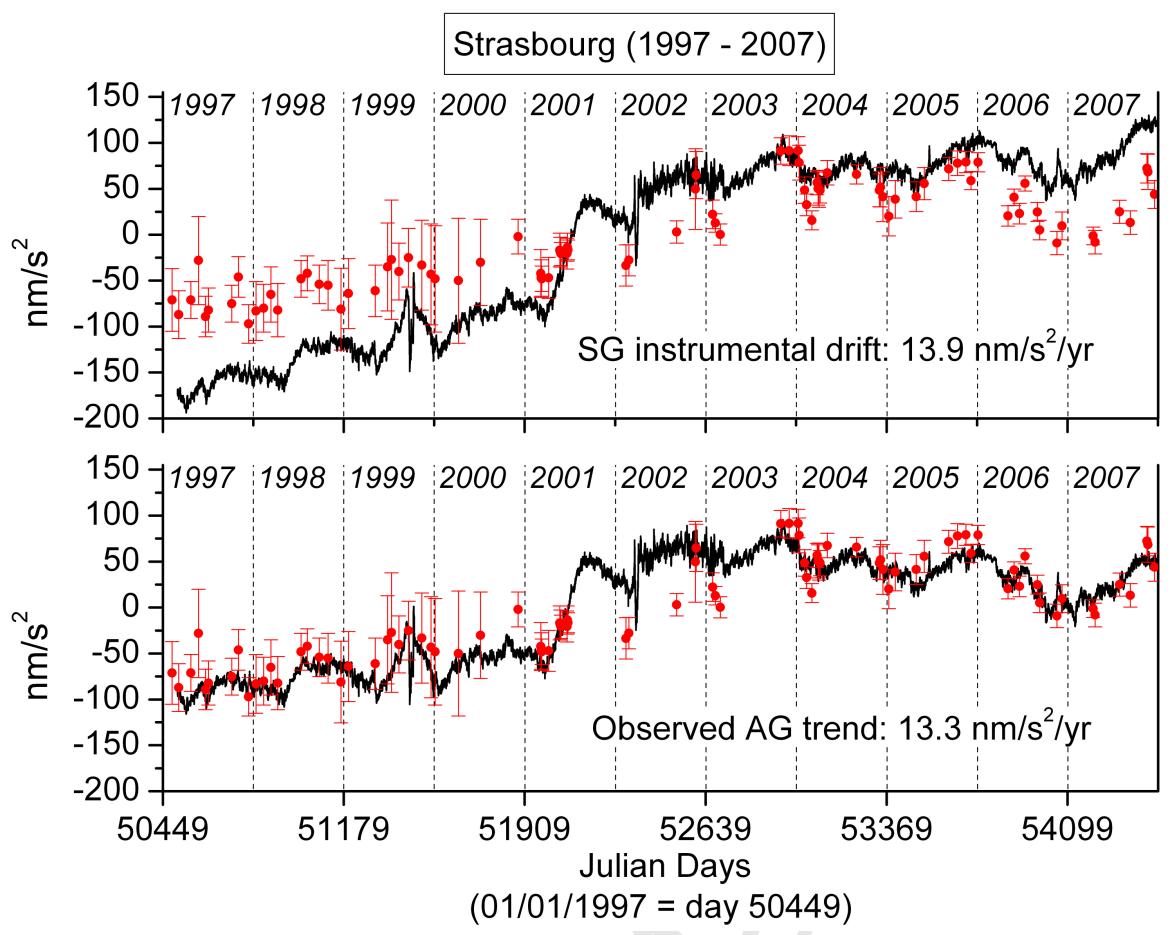

Fig. 3 
(a)
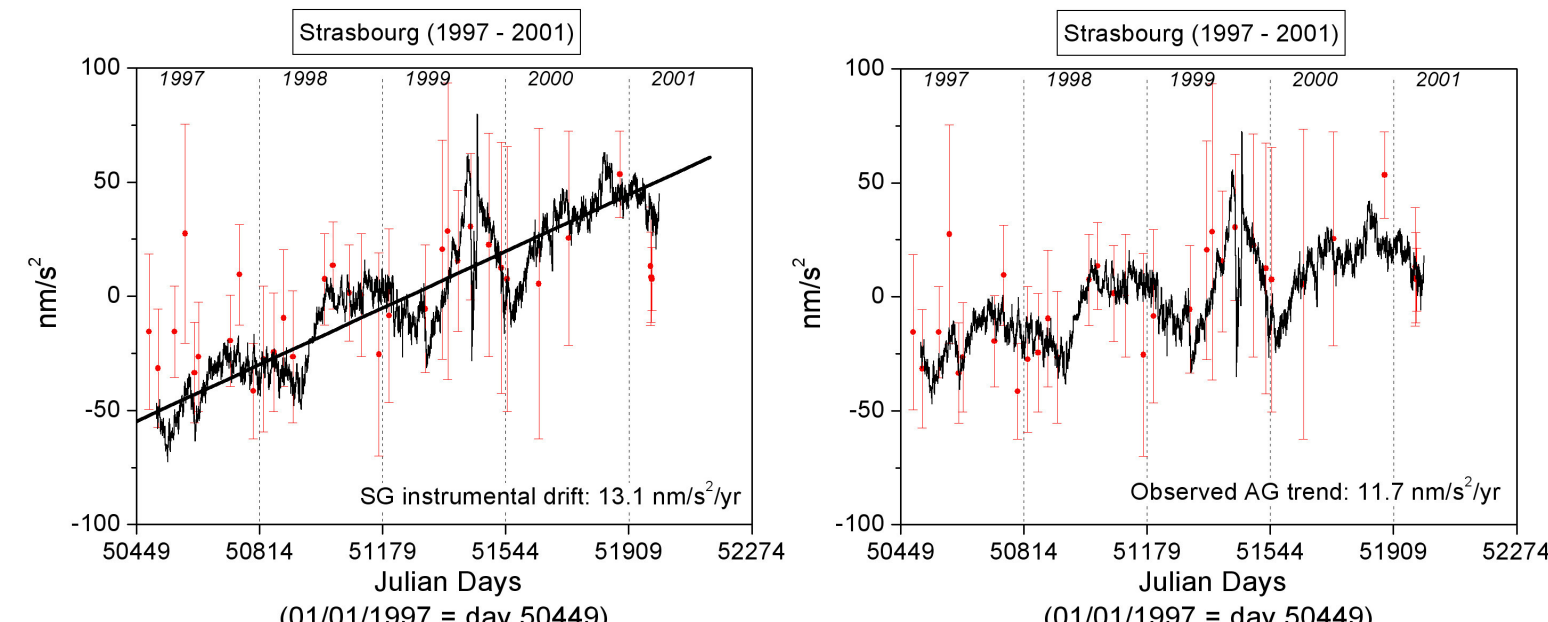

(b)
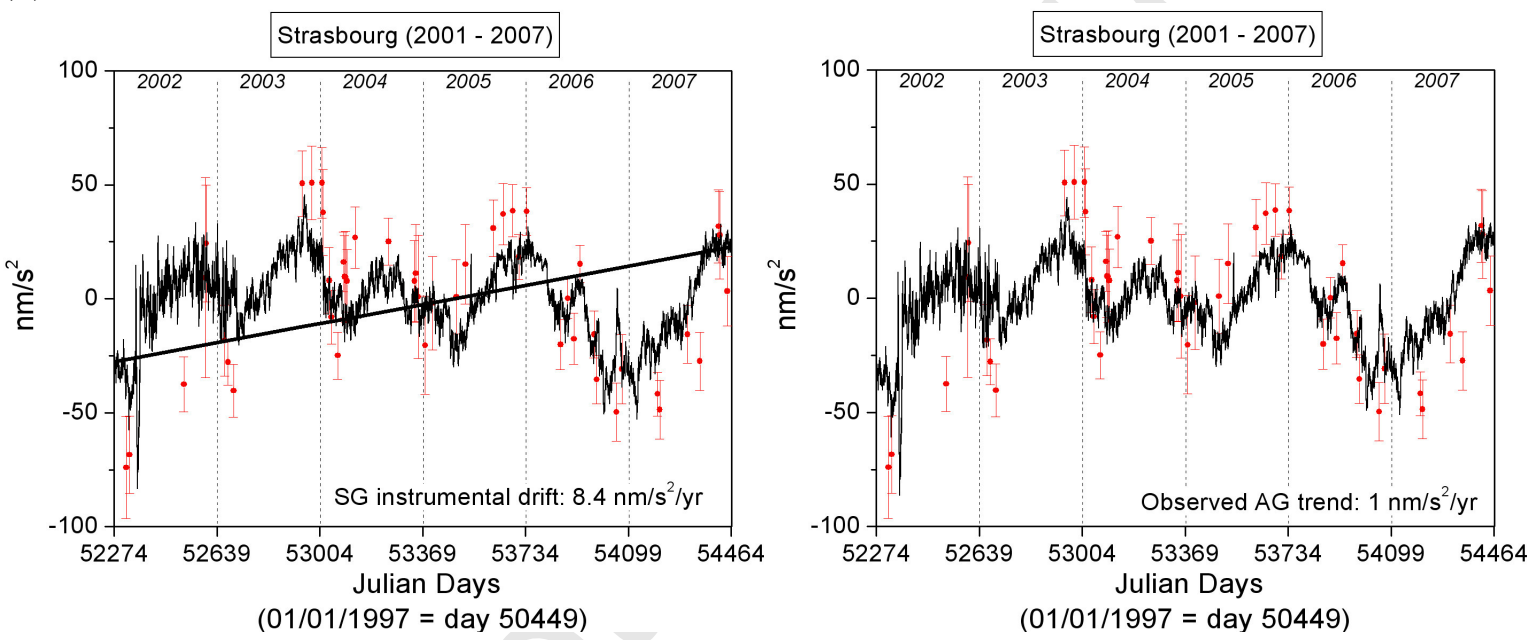

Fig. 4 

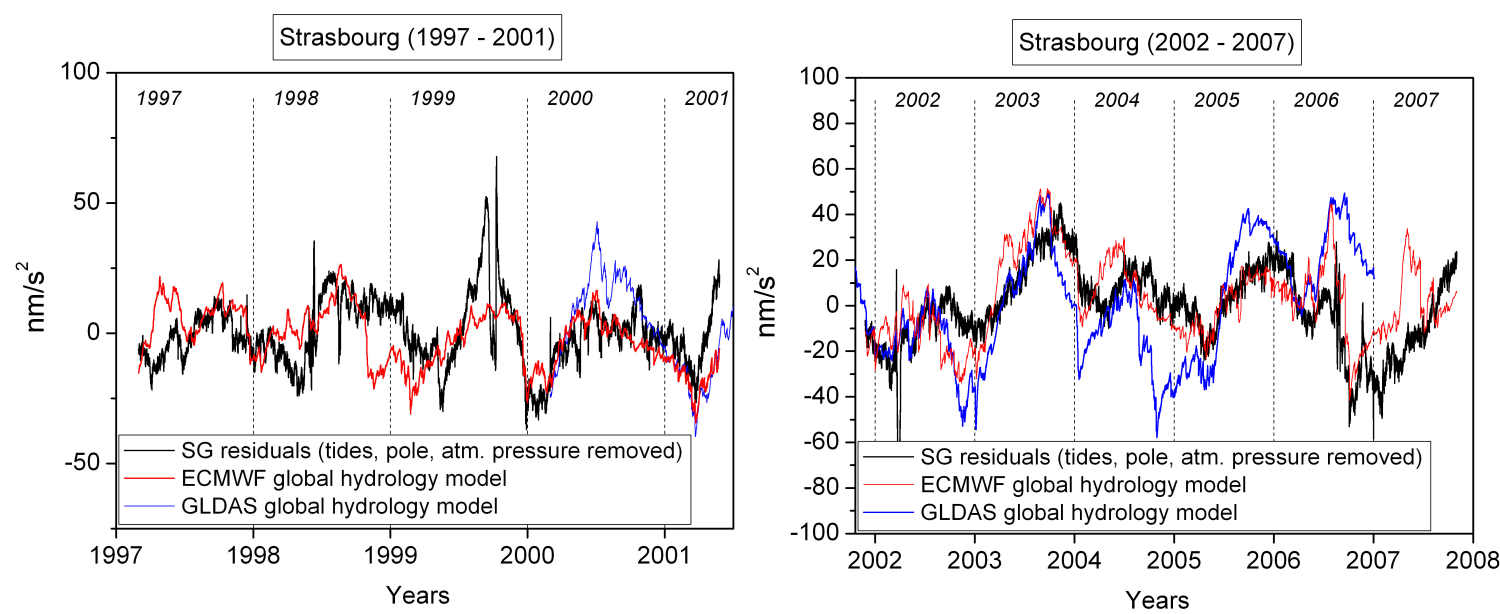

Fig. 5 


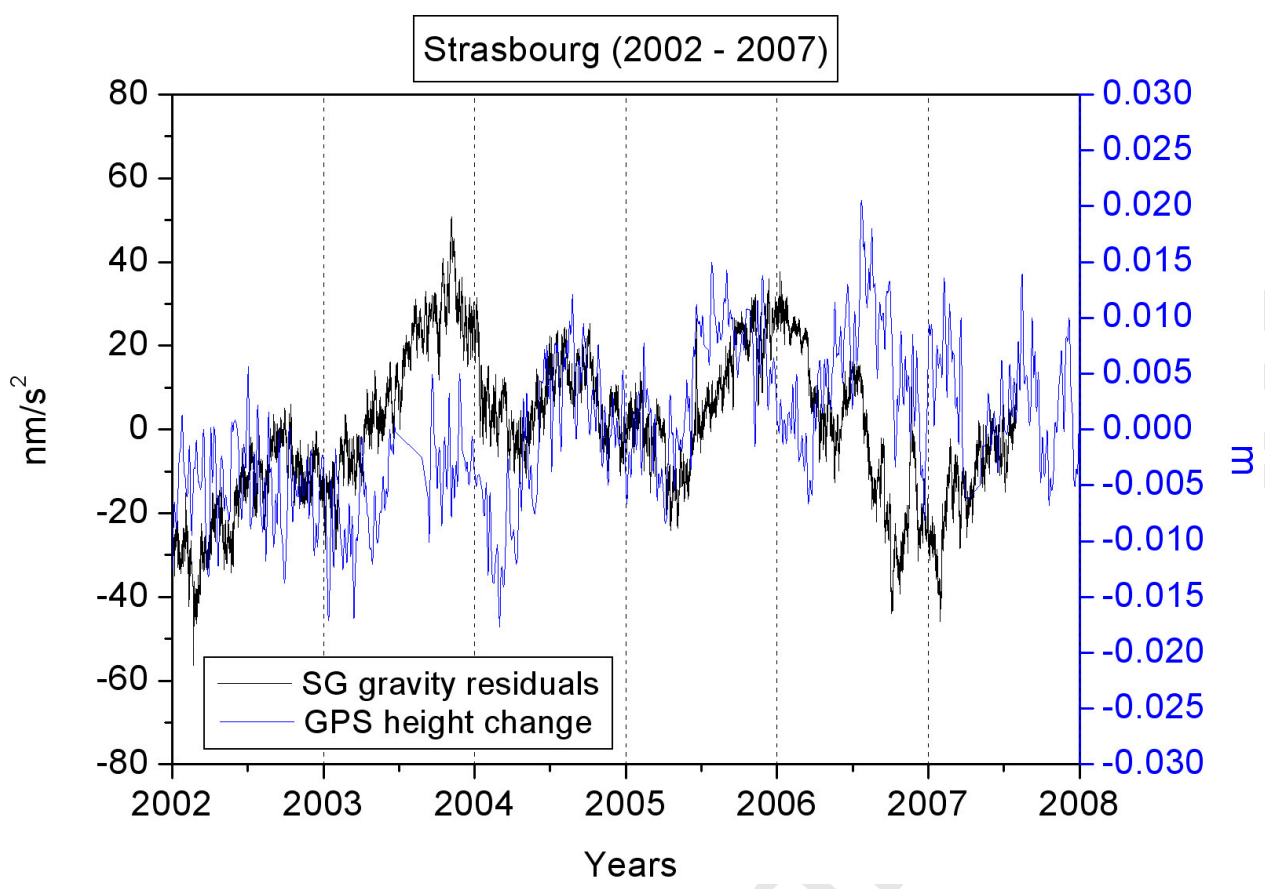

Fig. 6 


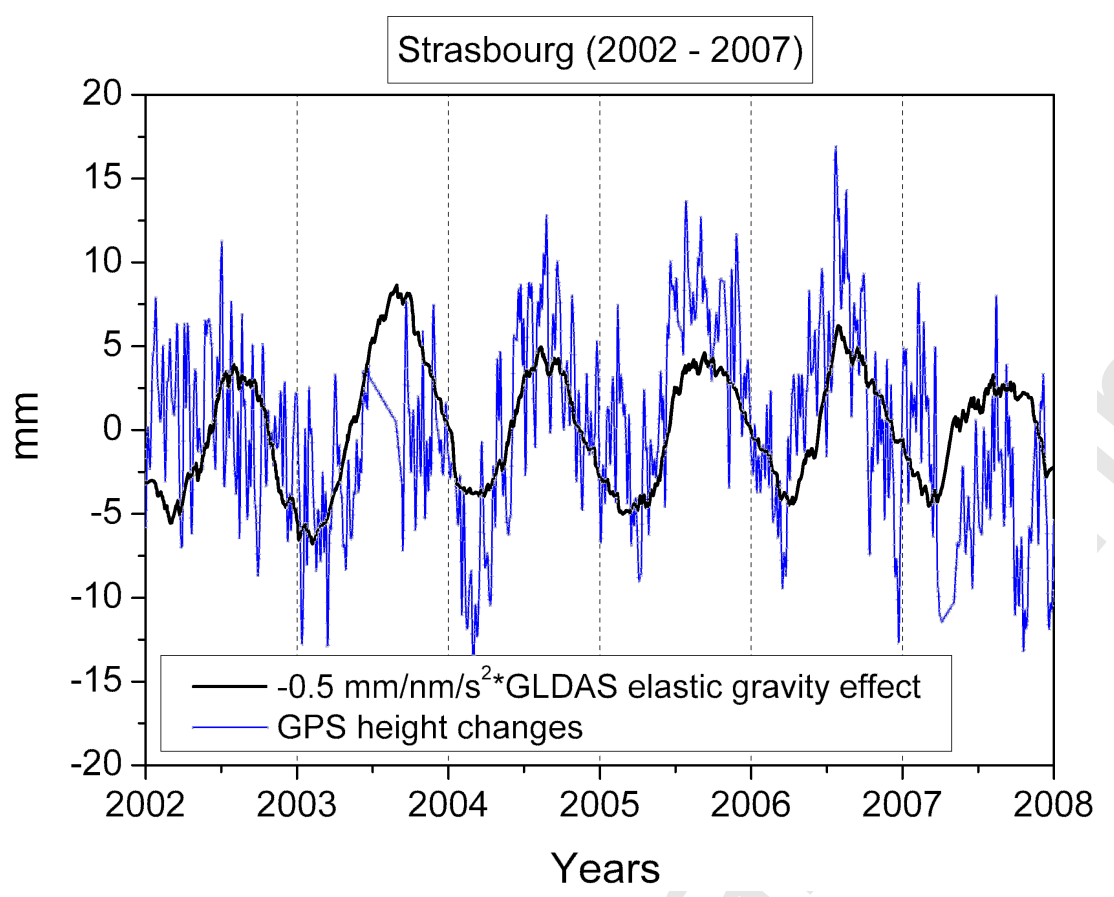

Fig. 7 